\title{
Effect of Music Intervention on Anxiety in Patients Undergoing Periodontal Surgery: A Pilot Study
}

\author{
Ob-Om Buranavichetkul, ${ }^{1}$ Suchitra Klinklai, ${ }^{2}$ Thitiwan Teparat-Burana ${ }^{2 *}$ \\ ${ }^{1}$ Faculty of Medicine, Thammasat University, Thailand \\ ${ }^{2}$ Faculty of Dentistry, Mahidol University, Thailand
}

\begin{abstract}
Objective: The effect of music listening on blood pressure (BP), heart rate (HR) and anxiety level (AL) was investigated for thirty patients undergoing periodontal surgery.

Methods: A total of sixty patients referred for periodontal surgery were randomized into two equal groups as i) without music (control), and ii) with music (test). Before and after the procedure, BP and HR were recorded. All patients responded to AL assessment using facial image scale (FIS) before and after surgery. After listening to music before and during the procedure BP, HR and AL were assessed for the test group.
\end{abstract}

Results: Systolic BP (SBP) in both groups increased but showed no statistically significant difference between the two groups ( $p>0.05$ ). Diastolic BP (DBP) increased after treatment with no statistically significant difference $(\mathrm{p}>0.05)$ between test $(4.70 \mathrm{mmHg})$ and control $(6.20 \mathrm{mmHg})$ groups. HR decreased after the procedure in both test and control groups ( $8.40 \mathrm{vs.} 9.03$ beats per minute) with no statistically significant difference between the two groups ( $p>0.05)$.AL after the procedure decreased in both groups but with no statistically significant difference $(p>0.05)$.

Conclusion: Only HR and AL decreased after music intervention.However, no differences in BP, HR and AL were found between groups with and without music.

This clinical trial was registered with TCTR (Thai Clinical Trials Registry) code TCTR20190411004.

Keywords: Music, anxiety, Periodontal surgery, Blood pressure, Heart rate

\section{Introduction}

Anxiety when visiting the dentist for dental treatment is ranked the 5th highest among feared situations ${ }^{1}$ with only a small group of patients having no anxiety in the dental environment. Researchers in the Netherlands reported that almost $62 \%$ of patients suffer anxiety from dental treatment. ${ }^{2}$ Factors often linked to anxiety-related incidents include personal characteristics, fear about pain, previous dental experiences, the influence of a family member or co-worker expressing dental anxiety and hemophobia. ${ }^{2-8}$ Physical responses of patients with dental anxiety include increased blood pressure (BP), heart rate (HR) and respiratory rate. ${ }^{9,10}$ A National Health
Survey in 2012 by the Thai Ministry of Public Health reported the occurrence of periodontitis in the working age group at $15.6 \%$ and in the elderly at $32.1 \%{ }^{11}$ Treatment of severe periodontitis cases often requires periodontal surgery. ${ }^{12}$

Patients were requested to answer the Dental Anxiety Scale (DAS) questionnaire while waiting for treatment.Results showed that tooth extraction, periodontal surgery and scaling caused significant dental anxiety, ${ }^{13}$ while $12.1 \%$ of patients referred for periodontal treatment reported extreme anxiety. Main reasons were given as fear of pain and poor dental treatment experience.Patients

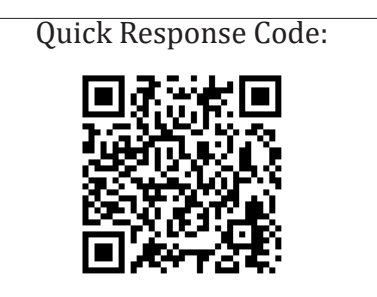

*Corresponding author: Thitiwan Teparat-Burana, Faculty of Dentistry, Mahidol University, 6 Yothi Street, Rajthevi, Bangkok 10400, Thailand

Received: 14 January, 2021

Published: 25 January, 2021

Citation: Buranavichetkul O, Klinklai S, Teparat-Burana T. Effect of Music Intervention on Anxiety in Patients Undergoing Periodontal Surgery: A Pilot Study. SOJ Den Oral Disor. 2021;1(1):1-6. DOI: 10.53902/SOJDOD.2021.01.000503 
with high anxiety before periodontal surgery have usually experienced more pain than those with low anxiety levels. ${ }^{14}$ Effective management of dental anxiety includes dentist-patient communication, relaxation therapy and conscious sedation (inhalation of nitrous oxide or anxiolytic agents such as diazepam). There are potential side effects of medications. Patients with extreme anxiety may require general anesthesia. ${ }^{15}$ Patients with dental anxiety often prefer other relaxation methods rather than taking medication to reduce any possible side effects. ${ }^{16}$

Music helps to relieve stress and anxiety by its calming effect on both the nervous system and the host immune system due to several underlying mechanisms which include 1) autonomic nervous responses by suppressive action on the sympathetic nervous system, leading to decreased adrenergic activity and neuromuscular arousal, and 2) by triggering the limbic system to release endorphins. ${ }^{17}$ The level of secretory immunoglobulin A (S-IgA) as a patient stress marker reduced while listening to music during dental treatment. ${ }^{18}$ Appropriate music rhythm for relaxation was determined as 70-80 beats per minute. ${ }^{19}$ Meyer LB reported that music used for relaxation which related to the culture of the listener had a greater effect than music that lacked familiarity. ${ }^{20}$ Using headphones to listen to music during medical treatment increased anxiety because the patient could not hear instructions or information from the treatment providers. ${ }^{21}$ Using relaxing music with a slow tempo, no lyrics and instrumentation using strings, woodwind and piano is recommended in dental practices. ${ }^{17}$
Studies using music intervention to reduce dental anxiety compared patients that were listening and those not listening to music while undergoing surgical extraction of an impacted mandibular third molar. Results demonstrated statistically significant intraoperative anxiety reduction in the music listening group Singh et al. ${ }^{22}$ Studied the effect of music on pediatric patients who had never undergone dental treatment for tooth extraction. Patients listening to music during treatment showed statistically significant decreased anxiety. Systolic blood pressure (SBP) decreased and HR reduced at a statistically significant level in the group listening to music compared to the group without music. ${ }^{23}$ On the contrary, Maybodi FR et al. ${ }^{24}$ demonstrated that listening to music during periodontal surgery did not decrease BP and anxiety level (AL). ${ }^{24}$ Nevertheless, the number of subjects were limited which could not provide a strong evidence.Recently, Kocaman\& Cetin Benli ${ }^{25}$ studied the effects of music on vital signs and dental anxiety prior to periodontal surgery.Patients listening to the music showed statistically significant decreased BP and HR. But this study did not evaluate the vital signs and anxiety level after periodontal surgery. ${ }^{25}$ Previous studies on the effect of music to reduce dental anxiety demonstrated conflicting results. Only 2 studies have examined the effect of music on dental anxiety during periodontal surgery. Therefore, here, the effect of music during periodontal surgery was compared for BP, HR and $\mathrm{AL}$ of patients. We hypothesized that music intervention reduced anxiety inpatients regarding to both vital signs and self-reported anxiety assessment.

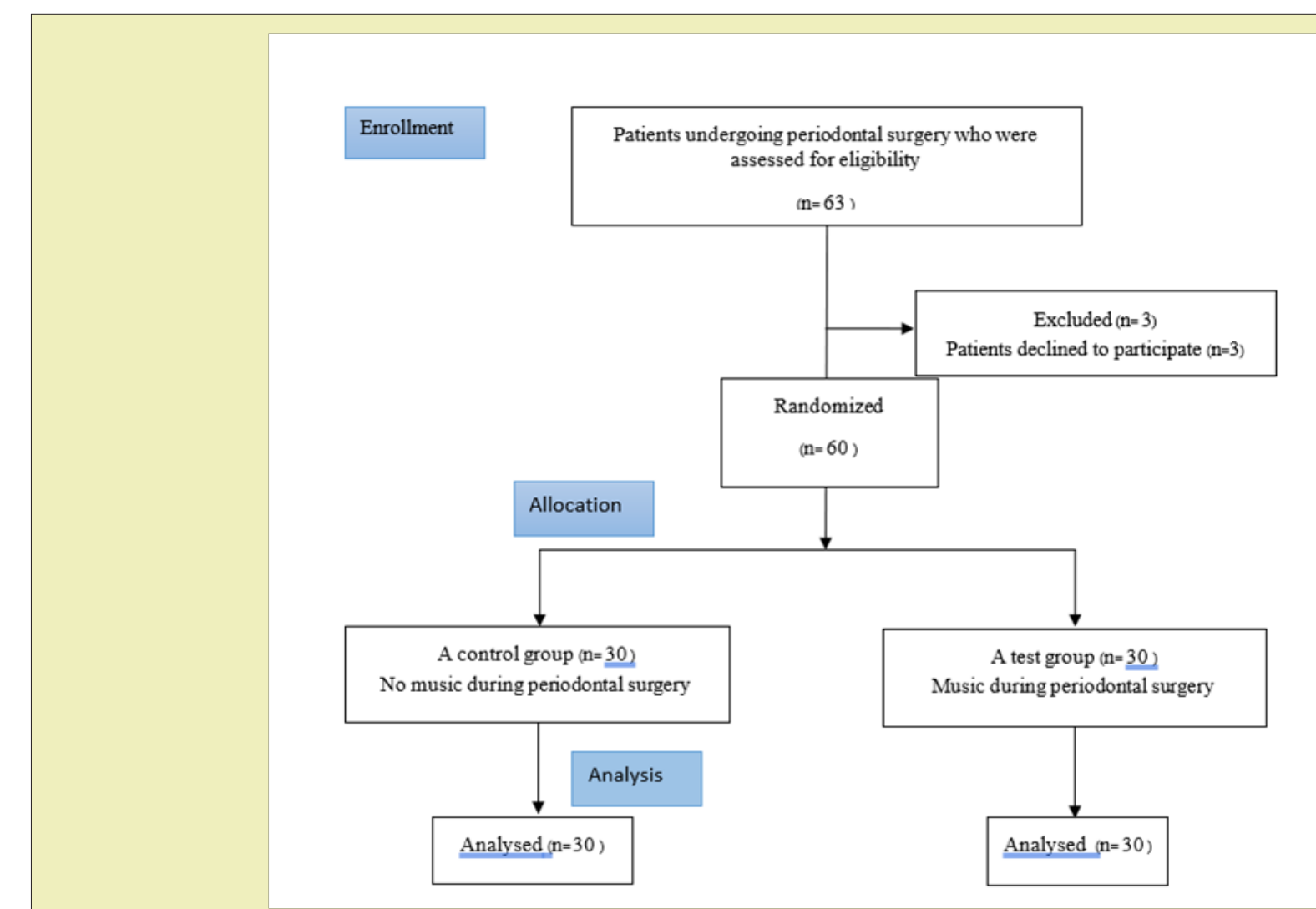

Figure 1: CONSORT flow diagram of the progress through phases of the study. 


\section{Materials and methods}

This study was approved by the Ethics Committee of the Faculty of Dentistry/Faculty of Pharmacy, Mahidol University, and Institutional Review Board. All 63 patients referred to the Periodontal Clinic, Faculty of Dentistry. Mahidol University for periodontal surgery between March 25, 2019 and August 29, 2019 were invited to participate in the study.Sixty patients were recruited. Inclusion criteria were as follows: 1) age>18 years, 2) no history of hearing loss or mood disorders, and 3) no contraindication for periodontal surgery under local anesthesia.Exclusion criteria included taking antianxiety medication or high pre-treatment anxiety level (facial image scale, FIS $=5$ ) ${ }^{26}$ Informed consent was obtained from all participants included in the study.Patients were randomly divided into two groups as a music treated group (test) and a control group, each consisting of 30 subjects (Figure1).

Basic demographic data were collected including gender, age, and previous experience of periodontal surgery (yes or no). Before the surgery, routine preoperative BP and HR were measured by using a digital sphygmomanometer (Omron, Matsusaka Co Ltd, Japan) and recorded and an AL test (FIS) was given to all patients.A score of 1 indicated no anxiety and a score of 5 indicated the highest anxiety. ${ }^{26}$ Patients in the control group were seated in the operating room for at least 10 minutes before they were anesthetized, while patients in the test group listened to music before receiving local anesthesia and continued listening to music until the treatment was completed.Instrumental music by Chamrat Sewataporn from

Table 1: General characteristics of participants the Nirvana series was played. This was reported to be the most favoured relaxing music for patients waiting for caesarean surgery. ${ }^{27}$ BP, HR, type and the amount of local anesthesia were recorded immediately after completion of periodontal surgery as a routine procedure.All patients were assessed for post treatment AL according to FIS.

\section{Statistical Analysis}

Statistical analyses were completed using SPSS computer software (SPSS, Inc., Chicago, IL, USA). Normality of the data was analysed following the Kolmogorov-Smirnov test. An independent t-test was used to compare mean values of systolic and diastolic BP, HR and $\mathrm{AL}$ as well as mean differences between the two groups.

\section{Results}

\section{a) Demographic analysis}

There were 17 male (56.7\%) and 13 (43.3\%) female patients in the test group and 20 male (66.7\%) and 10 (33.3\%) female patients in the control group. Mean age of participants in the test group was $48.03 \pm 14.02$ years and in the control group 52.53 \pm 12.18 years. Patients with previous experience with periodontal surgery in the test group were $50 \%$ and $43.3 \%$ in the control group. Mean durations of surgical procedure in the test and control groups were $163.9 \pm 43.36$ and $166.37 \pm 43.63$ minutes, respectively. There were no significant differences in gender distribution, age, previous experience of periodontal surgery, duration of surgery, type of local anesthesia and the amount of local anesthesia ( $p>0.05)$ (Table 1).

\begin{tabular}{|c|c|c|c|}
\hline & Test $(n=30)$ & Control $(n=30)$ & p-value \\
\hline \multicolumn{3}{|l|}{ Gender n(\%) } & \multirow{3}{*}{0.426} \\
\hline Male & $17(56.7)$ & $20(66.7)$ & \\
\hline Female & $13(43.3)$ & $10(33.3)$ & \\
\hline Age(years) mean $\pm S D$ & $48.03 \pm 14.02$ & $52.53 \pm 12.18$ & 0.19 \\
\hline \multicolumn{3}{|l|}{$\begin{array}{l}\text { Previous experience of periodontal } \\
\text { surgery } n(\%)\end{array}$} & \multirow{3}{*}{0.605} \\
\hline Yes & $15(50.0)$ & $13(43.3)$ & \\
\hline No & $15(50.0)$ & $17(56.7)$ & \\
\hline $\begin{array}{l}\text { Duration of surgical procedure } \\
\text { (minutes) mean } \pm S D\end{array}$ & $163.90 \pm 43.36$ & $166.37 \pm 43.63$ & 0.827 \\
\hline \multicolumn{4}{|l|}{ Type of local anesthesia n(\%) } \\
\hline $\begin{array}{c}\text { Scandonest } 2 \% \text { with epinephrine } \\
1: 100,000\end{array}$ & $25(83.3)$ & $20(66.7)$ & \multirow{2}{*}{0.136} \\
\hline $\begin{array}{c}\text { Scandonest } 3 \% \text { without vasocon- } \\
\text { strictor }\end{array}$ & $5(16.7)$ & $10(33.3)$ & \\
\hline \multicolumn{4}{|l|}{$\begin{array}{l}\text { The amount of local anesthesia } \\
\text { (cartridge) } n(\%)\end{array}$} \\
\hline $1-2$ & $18(60.0)$ & $17(56.7)$ & \multirow{3}{*}{0.59} \\
\hline 3 & $5(16.7)$ & $8(26.7)$ & \\
\hline $4-5$ & $7(23.3)$ & $5(16.7)$ & \\
\hline
\end{tabular}




\section{b) Vital sign analysis}

Mean systolic BP (SBP), diastolic BP (DBP) and HR are listed in Table 2. Mean SBP, DBP and HR values were not significantly different between test and control groups both before and after periodontal surgery ( $p>0.05)$. Mean value of SBP increased in both test $(1.37 \mathrm{mmHg})$ and control $(3.83 \mathrm{mmHg})$ groups. Comparison of mean SBP differences between the two groups showed no significant difference $(p>0.05)$. Mean value of DBP increased in both test $(4.70 \mathrm{mmHg})$ and control $(6.20 \mathrm{mmHg})$ groups with no significant difference between the two groups ( $p>0.05)$. Decrease in HR in both test ( 8.40 beats/minute) and control (9.03beats/minute) groups showed no significant difference ( $p>0.05$ ) (Table 2).

Table 2: Vital signs of participants

\begin{tabular}{|c|c|c|c|c|}
\hline \multirow{2}{*}{ Vital signs } & $\begin{array}{c}\text { Phase of periodontal } \\
\text { surgery }\end{array}$ & Test (n=30) & Control (n=30) & p-value \\
\hline \multirow{3}{*}{ SBP (mmHg) } & Before & $120.93 \pm 13.81$ & $123.47 \pm 16.03$ & 0.514 \\
\cline { 2 - 5 } & After & $122.30 \pm 26.65$ & $127.30 \pm 16.56$ & 0.386 \\
\cline { 2 - 5 } & Mean difference & $1.37 \pm 24.84$ & $3.83 \pm 15.79$ & 0.648 \\
\hline \multirow{3}{*}{ DBP (mmHg) } & Before & $68.87 \pm 9.40$ & $70.30 \pm 16.55$ & 0.682 \\
\cline { 2 - 5 } & After & $73.57 \pm 9.94$ & $76.50 \pm 9.25$ & 0.241 \\
\hline \multirow{3}{*}{ HR (beats/minute) } & Mean difference & $4.70 \pm 11.74$ & $6.20 \pm 16.30$ & 0.684 \\
\cline { 2 - 5 } & Before & $76.60 \pm 12.45$ & $77.57 \pm 11.95$ & 0.76 \\
\cline { 2 - 5 } & After & $68.20 \pm 12.17$ & $68.53 \pm 16.43$ & 0.929 \\
\hline
\end{tabular}

\section{c) Anxiety analysis}

Mean anxiety scores were not significantly different between test and control groups both before and after periodontal surgery $(p>0.05)$.Mean anxiety score decreased in both test (0.33) and control $(0.80)$ groups with no significant difference between the two groups ( $p>0.05$ ) (Table 3).

Table 3: Anxiety levels of participants

\begin{tabular}{|c|c|c|c|}
\hline FIS score & Test(n=30) & Control (n=30) & p-value \\
\hline \multicolumn{4}{|c|}{ Before periodontal surgery } \\
\hline 1 & $6(20.0)$ & $6(20.0)$ & \\
\hline 2 & $8(26.7)$ & $9(30.0)$ & \\
\hline 3 & $15(50.0)$ & $10(33.3)$ & 0.679 \\
\hline 4 & $1(3.3)$ & $5(16.7)$ & \\
\hline mean \pm SD & $2.37 \pm 0.86$ & $2.47 \pm 1.01$ & \\
\hline \multicolumn{4}{|c|}{ After periodontal surgery } \\
\hline 1 & $10(33.3)$ & $15(50.0)$ & \\
\hline 2 & $10(33.3)$ & $10(33.3)$ & \\
\hline 3 & $9(30.0)$ & $5(16.7)$ & 0.091 \\
\hline 4 & $1(3.3)$ & $0(0.0)$ & 0.094 \\
\hline mean \pm SD & $2.03 \pm 0.89$ & $1.67 \pm 0.76$ & \\
\hline Mean difference & $-0.33 \pm 1.09$ & $-0.80 \pm 1.03$ & \\
\hline
\end{tabular}

\section{Discussion}

This study evaluated the effect of music to reduce patient anxiety during periodontal surgery. Several previous studies investigated short duration of music listening (e.g., 5 minutes9) which may not be sufficient to impact anxiety management. ${ }^{17}$ In our study, patients in both groups listened to music for at least 10minutes before local anesthetic injection. Parameters used were BP, HR and AL FIS score. Results from this clinical study demonstrated that both SBP and DBP increased after the procedure, with no significant dif- ference in SBP and DBP change between the two groups. HR and FIS decreased after surgery in both groups but difference in change between the two groups was not significant. Results demonstrated that listening to music during periodontal surgery does not affect $\mathrm{AL}$ according to vital signs. Our results concurred with a previous study that reported no effect of music on BP decrease. AL decreased after periodontal surgery in both groups but with no significant difference between music and control groups. This finding contrasted with another study that demonstrated no change in AL from listening to music. ${ }^{24}$

Several questionnaires based scales to assess the dental anxiety of patients have been used. Modified Dental Anxiety Scale (MDAS) is the most commonly used and is a reliable and valid tool to assess dental anxiety. ${ }^{28}$ However, a Thai version of MDAS is still lacking. The process of translation and adaptation of instruments is Needed before it can be used.Therefore, this study used FIS which has an evidence of validation to assess the dental anxiety of patients. ${ }^{28}$

Previous experience of periodontal surgery may be in part in patient anxiety level. There was an increase in anxiety level with the first surgery appointment but it was a decrease with later surgical appointments. ${ }^{14}$ The number of patients with previous experience of periodontal surgery was no significant differences between the two groups. Therefore, the patient previous experience of periodontal surgery may not be an impact on the results of this study.

The effects of local anesthesia may be in part in patient blood pressure status.However, the previous studies reported no significant changes in blood pressure in the patients who received local anesthesia with or without vasoconstrictors both before and after tooth extraction. ${ }^{29-31}$ Both type and the quantity of local anesthesia used in both groups was no significant differences in this study. Music preference of patients plays an important role in anxiety management. ${ }^{17}$ However, a meta-analysis reported that music selection 
based on research had a greater effect than based on participant preference. ${ }^{32}$ Here, researcher-selected music, reported to be the most favoured relaxing music for patients waiting for caesarean surgery, ${ }^{27}$ was used because there were several dental chairs in the operating room and patient-preferred music was not possible without using headphones. These may increase patient anxiety by impacting communication with the dentist even though they reduce unpleasant noise from the procedure e.g., drilling or professional conversations between surgeon and staff. ${ }^{17}$ One recommendation suggested using noise-cancelling headphones which masked dental noise but allowed patients to communicate with the dentist via a microphone. ${ }^{33}$ Furthermore, the systematic review from 19studies was concluded that music can reduce the self-reported anxiety levels in hospital patients. However, there was no effect on the patients who were undergoing 'unpleasant' medical procedures. ${ }^{34}$ Periodontal surgery can be considered as an "unpleasant" medical procedure. These may, in part, resulted in no differences between 2groups in this study.

Although, as a pilot study, the sample size was not large, the findings which have been analysed support the conclusion that listening to music during periodontal surgery does not affect patient anxiety. Further studies on a larger sample population are needed. In addition, if the anxiety level changes were evaluated at different time points: before, during and after the procedure, this would have provided more information about the effects of music in anxiety reduction.

Binaural beats are special sounds perceived when two auditory stimuli of different frequencies are presented to each ear. The use of these beats as a therapeutic tool has recently gained interest among neurophysiologists and clinicians. Binaural beats reportedly influence the brain through the entrainment of brainwaves and can be used to reduce anxiety and increase pain threshold. ${ }^{35}$ Binaural beat with music audio reduced AL, SBP and HR in patients undergoing cataract surgery performed under local anesthesia. ${ }^{36}$ Further studies on the effect of binaural beat embedded music intervention during periodontal surgery are required to assess the reduction of patient anxiety, possibly resulting in improved patient compliance and surgical outcomes.

\section{Conclusion}

The results from this pilot study demonstrated that music intervention during periodontal surgery neither affect patient vital signs nor anxiety. Further studies with a larger sample size are needed to confirm the results from this study.

\section{Acknowledgments}

None.

\section{Author Contribution}

Ob-OmBuranavichetkul provided a conception of the study, collected data, performed conduction of experiments and wrote introduction. SuchitraKlinklai collected data. Thitiwan Teparat-Burana designed and supervised the study, reviewed statistical analysis, wrote results and discussion section and gave final approval for the version submitted for publication. All authors reviewed and approved the final version of the manuscript.

\section{Funding}

No external funding was received.

\section{Conflicts of interest}

Author declares that there is no conflict of interest.

\section{References}

1. Agras S, Sylvester D, Oliveau D. The epidemiology of common fears and phobia. Compr Psychiatry. 1969;10(2):151-156.

2. Eli I, Uziel N, Blumensohn R, et al. Modulation of dental anxiety -the role of past experiences, psychopathologic traits and individual attachment patterns. Br Dent J. 2004;11:689-694.

3. Moore R, Birn H, Kirkegaard E, et al. Prevalence and characteristics of dental anxiety in Danish adults. Community Dent Oral Epidemiol. 1993;21(5):292-296.

4. Milgrom P, Fiset L, Melnick S, et al. The prevalence and practice management consequences of dental fear in a major US city. J Am Dent Assoc. 1988;116(6):641-647.

5. Economou GC. Dental Anxiety and Personality: Investigating the Relationship Between Dental Anxiety and Self-Consciousness. J Dent Educ. 2003;67:970-980.

6. Kleinknecht RA, Klepac RK, Alexander LD. Origins and characteristics of fear of dentistry. J Am Dent Assoc. 1973;86(4):842-848.

7. Woolgrove J, Cumberbatch G. Dental anxiety and regularity of dental attendance. J Dent. 1986;14(5):209-213.

8. Locker D, Shapiro D, Liddell A. Overlap between dental anxiety and blood injury fears: psychological characteristics and response to dental treatment. Behav Res Ther. 1997;35(7):583-590.

9. Aitken JC, Wilson S, Coury D, et al. The effect of music distraction on pain, anxiety and behavior in pediatric dental patients.Padiatr Dent. 2002;24(2):114-118.

10. Howitt JW, Stricker G. Child patient response to various dental procedures. J Am Dent Assoc. 1965;70:70-74.

11. Bureau of Dental Health. The $7^{\text {th }}$ National Oral Health Survey 2012.

12. Newman MG, Takei HH, Klokkevold PR, et al. The treatment plan. In Clinical Periodontology. $10^{\text {th }}$ ed. Missouri, USA: W.B. Saunders. 2006: p. 626-629.

13. Stablotz A, Peretz B. Dental anxiety among patients prior to different dental treatments. Int Dent J. 1999;49(2):90-94.

14. Fardal 0 , Hansen BF. Interviewing self-reported highly anxious patients during periodontal treatment. J Peridontol. 2007;78(6):1037-1042.

15. Hmud R, Walsh LJ. Dental anxiety: causes, complications and management approaches. J Minim Interv Dent. 2009;2:67-78.

16. Armfield JM, Heaton LJ. Management of fear and anxiety in dental clinic: a review. Aust Dent J. 2013;58(4):390-407.

17. Bradt J, Teague A.Music interventions for dental anxiety. Oral Dis. 2018;24(3):300-306.

18. Golf LC, Pratt RR, Madrigal JL.Music listening and S-IgA levels in patients undergoing a dental procedure. Int J Arts Med. 1997;5:22-26.

19. Cook JD.The therapeutic use of music: A literature review. Nurs Forum. 1981;20(3):252-266.

20. Meyer LB. Emotion and meaning in music. Chicago: University of Chicago Press; 1956.

21. Kwekkeboom K. Music versus distraction for procedural pain and anxiety in patients with cancer. Oncol Nurs Foru. 2003;30(3):433-440.

22. Kim YK, Kim SM, Myoung H. Musical intervention reduces patients' anxiety in surgical extraction of an impacted mandibular third molar. $J$ Oral Maxillofac Surg. 2011;69(4):1036-1045.

23. Singh D, Samadi F, Jaiswal J, et al. Stress reduction through audio distraction in anxious pediatric dental patients: an adjunctive clinical study. Int J ClinPediatr Dent. 2014;7(3):149-152.

24. Maybodi FR, Pandary MJ, Karami E, et al. The effect of music and lavender's aroma on patients anxiety, during periodontal surgery. JDMT. 2018;7(3):117-122.

25. Kocaman G, Cetin Benli N. The effects of music therapy on vital signs 
and dental anxiety prior to dental surgery. Konuralp Tip Dergisi. 2019;11(2):308-313.

26. Buchanan H, Niven N. Validation of a Facial Image Scale to assess child dental anxiety. Int J Paediatr Dent. 2002;12(1):47-52.

27. Buchanan H, Niven N. Further evidence for the validity of the Facial Image Scale. Int J Paediatr Dent. 2003;13(5):368-369.

28. Permpech R, Butsripoom B. The Effect of Music Therapy on Anxiety Level in Patients under Going Caesarean section. Journal of the Royal Thai Army Nurses. 2016;17(3):34-43.

29. Muhammad I, Zupash AK, Ibrahim K, et al.The effect of local anesthesia (lidocaine $2 \%$ ) with epinephrine $(1: 100,000)$ on blood pressure level of hypertensive patients reported to a tertiary care hospital, Peshawar, Pakistan. Biomed J Sci \& Tec Res. 2017;1(6):1687-1691.

30. Silvestre FJ, Salvador-Martinez I. Clinical study of hemodynamic changes during extraction in controlled hypertensive patients. Med Oral Patol Oral Cir Bucal. 2011;16(3):e354-e358.

31. Abu-Mustafa N, Aldawssary A, Assari A, et al.A prospective randomized clinical trial compared the effect of various types of local anesthetics cartridges on hypertensive patients during dental extraction. J ClinExp Dent. 2015;7(1):e84-e88.
32. Pelletier $\mathrm{C}$. The effect of music on decreasing arousal due to stress: a meta-analysis. J Music Ther. 2004;41(3):192-214.

33. Aitken J, Wilson S, Coury D, et al. The effect of music distraction on pain, anxirty and behavior in pediatric dental patients. Pediatr Dent. 2002;24(2):114-118.

34. Evans D. The effectiveness of music as an intervention for hospital patients: A systematic review. J AdvNurs. 2002;37(1):8-18.

35. Licklider J. On the frequency limits of the binaural beats. J AcoustSoc Am. 1950;22:468-473.

36. Wiwatwongwana D, Vichitvejpaisal P, Thaikruea L, et al. The effect of music with and without binaural beat audio on operative anxiety in patients undergoing cataract surgery: a randomized controlled trial. Eye (Lond). 2016;30(11):1407-1414. 